\title{
The Kasabach-Merritt syndrome: treatment with intermittent pneumatic compression
}

\author{
S E Aylett, A F Williams, D H Bevan, S J K Holmes
}

\begin{abstract}
A 6 week old infant presented with a giant angiomatous naevus of the leg complicated by chronic disseminated intravascular coagulation. The bleeding and laboratory abnormalities responded to intermittent pneumatic compression of the affected limb. This innocuous treatment should be considered in the Kasabach-Merritt syndrome.
\end{abstract}

Giant angiomatous naevi may be associated with life threatening complications, and if untreated, a mortality of $30 \%$. We report our experience with a 6 week old girl and her successful treatment.

\section{Case report}

St George's Hospital, London, Department of Child Health $S$ E Aylett A F Williams

Department of Haematology D H Bevan

Department of Paediatric Surgery S J K Holmes

Correspondence to: Dr S E Aylett, Department of Immunology, Institute of Child Health, 30 Guilford Street, London WCIN IEH.

Accepted 26 February 1990

(Arch DisChild 1990;65:790-1)

A 6 week old girl presented with a large subcutaneous angiomatous naevus involving the left leg from mid-thigh to mid-calf. A small swelling, thought to be a bruise, had been noted at birth. This had gradually increased in size, and been followed by rapid enlargement three days before presentation. The leg was swollen and indurated with superficial ecchymoses (fig 1A). The legs were equal in length. The haemoglobin concentration was $93 \mathrm{~g} / \mathrm{l}$, white cell count $9.6 \times 10^{9} / 1$, and the platelet count $23 \times 10^{9} / 1$. Clotting studies were normal.

Over the next week she developed generalised petechiae. Investigations nine days after presentation showed: haemoglobin concentration 120 $\mathrm{g} / \mathrm{l}$ (after transfusion), platelet count $16 \times 10^{9} / 1$, prothrombin time $17 / 13$ seconds, partial throm-
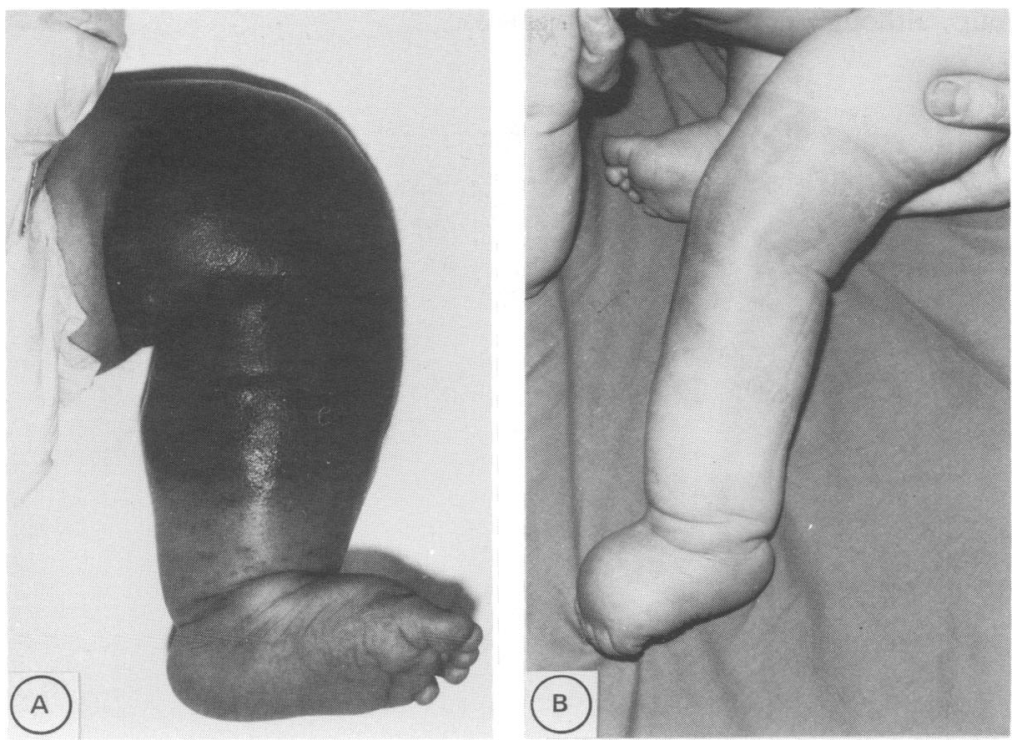

boplastin time $60 / 40$ seconds, and thrombin time 15/14 seconds. The fibrinogen concentration was low at $0.9 \mathrm{~g} / \mathrm{l}$ (normal $1.5-4.0$ ) and fibrinogen degradation products were detected (>32<64 mg/l). The antithrombin III concentration fell from $80 \mathrm{IU} / 100 \mathrm{ml}$ at presentation to $38 \mathrm{IU} / 100 \mathrm{ml}$ one week later. These findings confirmed the presence of a consumption coagulopathy. Over the next two weeks repeated blood and platelet transfusions were given (fig 2) because of further petechial haemorrhages, fundal haemorrhages, and rectal bleeding.

After consultation with the paediatric surgeon, a compressive bandage was applied while an intermittent pneumatic compressive device was being constructed. The platelet count rose to $>20 \times 10^{9} / 1$ and the petechiae resolved (fig 2). Treatment with intermittent pneumatic compression was started six days later and there was a further increase in platelet count to $>40 \times 10^{9} / 1$ (fig 2). No further platelet or blood transfusions were required, and the infant was discharged to continue treatment at home. The platelet count fell transiently at days 85 and 132 (fig 2) on two occasions when the pump was not applied for a full 24 hour period. Treatment has been continued for a period of 12 months, during which the naevus has partially resolved (fig 1B). The only complication has been chronic oedema of the leg, which is improving now treatment has been discontinued.

DESCRIPTION OF DEVICE

Treatment with intermittent pneumatic compression has been described in only three other cases of the Kasabach-Merritt syndrome. ${ }^{1}$ A 'Jobst extremity pump' has previously been employed using a blood pressure cuff of sufficient size to encircle the angiomatous naevus. The pressure applied is gradually increased to midway between the systolic and diastolic blood pressure, and the skin protected by a soft dressing. The pump is designed to compress for 90 seconds, and to rest for 30 seconds. Our medical physics department initially altered the electronic timer of a Huntleigh Flowtron Intermittent Compression System (AC 200/2) to cycle in this fashion (fig 3). In order to provide a portable battery operated system, a Laerdal suction pump was easily modified for use as a compressive device (details available on request).

Figure 1 Appearance of angiomatous naevus of left leg at $(A)$ presentation and $(B)$ showing partial resolution aged 9 months. 


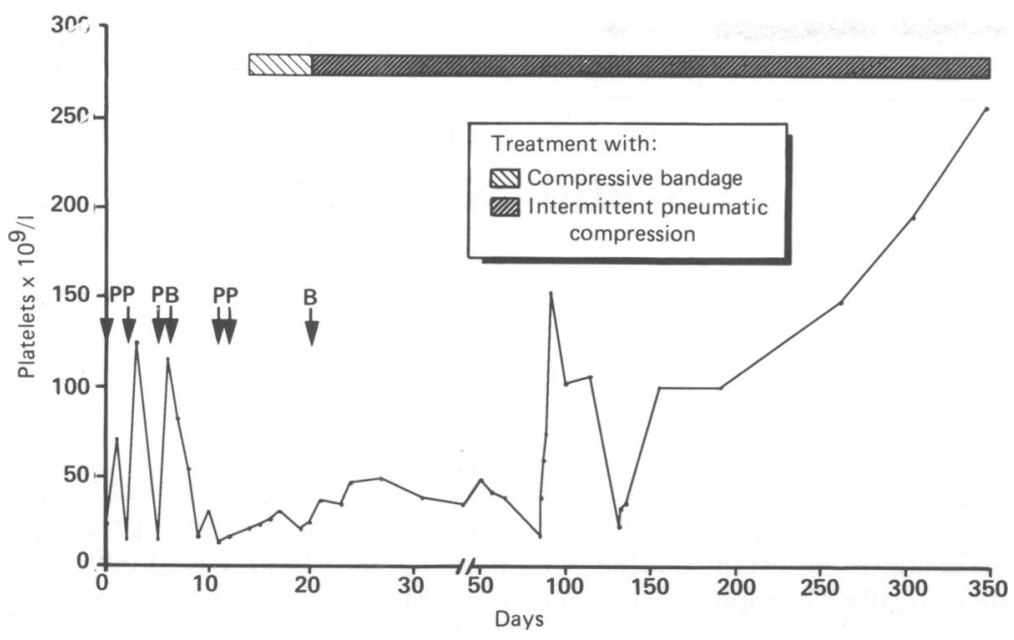

Figure 2 Platelet count and days after presentation. Platelet transfusions $(P)$ and blood transfusion $(B)$ are indicated.

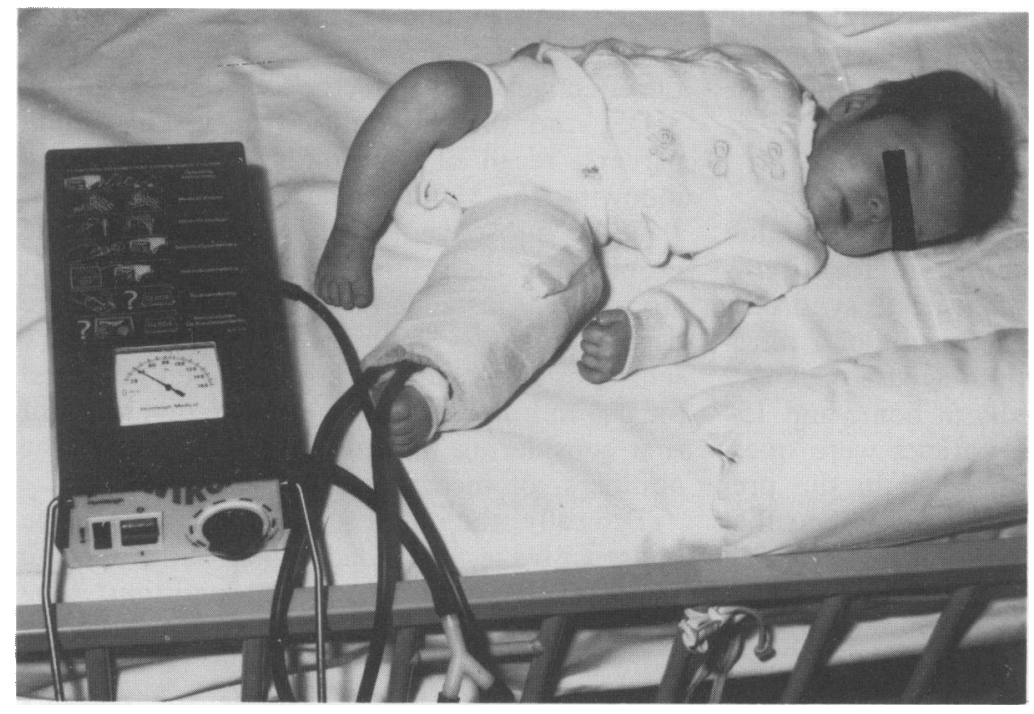

Figure 3 Infant attached to Huntleigh Flowtron compressive device. Two adult blood pressure cuffs sewn together encircle the angiomatous naevus, being held in place with lightweight bandage. These are attached to the device providing compression.

\section{Discussion}

Angiomatous naevi may enlarge rapidly in the first six months of life leading to local and generalised life threatening complications. ${ }^{1}$ These include: compression and scarring of adjacent structures or organs, differential limb growth (Klippel-Trenauny-Weber syndrome), and high output cardiac failure. The association with microangiopathic haemolytic anaemia, consumptive coagulopathy, and thrombocytopenia was first described in $1940 .^{2}$

Although the natural history of giant angiomatous naevi is of spontaneous regression with thrombosis and subsequent fibrosis, ${ }^{3}$ the mortality in untreated cases may be $30 \%,{ }^{4}$ coagulopathy being the major cause. ${ }^{5}$ It is believed that endothelial abnormalities and stasis within the lesion cause thrombosis with consumption of platelets and clotting factors. Radiolabelled platelets ${ }^{5}$ and fibrinogen ${ }^{3}$ accumulate within the angioma. Simultaneous samples from the angioma and peripheral blood indicate an intense coagulopathy localised to the angioma involving both coagulation and fibrinolysis. ${ }^{3}$

As the syndrome is rare and many forms of treatment have been used in the same case, assessment of efficacy has been difficult. Surgery is frequently complicated by uncontrollable bleeding, ${ }^{5}$ and embolisation may be associated with sepsis, inadvertent embolisation of vital organs, or vascular recanalisation. Systemic corticosteroids have been successful in reducing the size of angiomatous naevi and suppressing the coagulopathy. Large doses (prednisolone $2-5 \mathrm{mg} / \mathrm{kg} /$ day), ${ }^{45}$ however, and a prolonged course may be required. ${ }^{5}$ In a recent review of 153 cases radiotherapy in combination with steroids or surgery gave the best outcome, ${ }^{4}$ but such treatment carries obvious hazards. 5

Inhibitors of fibrinolysis such as tranexamic acid and aminocaproic acid, often given with cryoprecipitate, have reduced the size of angiomatous naevi and improved thrombocytopenia. ${ }^{5}$ There is, however, a theoretical risk of widespread thrombosis with this treatment. The antiplatelet agents ticlopidine and aspirin have been used with reported success in cases of Kasabach-Merritt syndrome, ${ }^{6}$ although the use of antiplatelet drugs in severe haemorrhagic thrombocytopenia also poses a theoretical risk.

The mechanism by which compression acts is not understood, but it probably empties the vessels and permits endothelial proliferation and thrombosis. Alternatively, trapped platelets may be liberated. ${ }^{1}$ This case confirms the previous observation that intermittent pneumatic compression can be effectively and safely carried out over a long period. ${ }^{1}$ It should be tried before pharmacological or other treatments.

We would like to thank Dr IG Lewis, consultant paediatrician, Redhill, Surrey and the medical physics department, St George's Hospital for help with management.

1 Stringel G. Giant haemangioma: treatment with intermittent pneumatic compression. I Pediatr Surg 1987;22:7-10.

2 Kasabach HH, Merritt KK. Capillary haemangioma with extensive purpura. Am J Dis Child 1940;59:1063-70.

3 Neidhert JA, Roach RW. Successful treatment of skeletal haemangioma and Kasabach-Merritt syndrome with aminocarpoic acid. Am $\mathcal{J}$ Med 1982;73:434-8.

4 El-Dessouky M, Azmy AF, Raine PAM, Young DG Kasabach-Merritt syndrome. F Peidat Surg 1988;23: Kasabach.

5 Larsen EC, Zinkham WH, Eggleston JC, Zitelli BJ Kasabach-Merritt syndrome: therapeutic considerations. Pediatrics 1987;79:971-80.

6 Kalifa C, Drouet L, Avril MF, et al. Traitement par ticlopidine et aspirine du syndrome de Kasabach-Merritt. Nouv Rev Fr Hematol 1984;26:132. 